This is a Reviewed Article

\title{
Toleranse og anerkjenning eller: Kva vil det seia å verdsetja mangfald?
}

Hans Marius Hansteen

University of Bergen

Hans.Hansteen@fof.uib.no 


\section{Abstract}

Even though "toleration" and "recognition" designate opposing attitudes (to tolerate something, implies a negative stance towards it, whereas recognition seems to imply a positive one), the concepts do not constitute mutually exclusive alternatives. However, "toleration" is often associated with liberal universalism, focusing on individual rights, whereas "recognition" often connotes communitarian perspectives, focusing on relations and identity. This paper argues that toleration may be founded on recognition, and that recognition may imply toleration. In outlining a differentiated understanding of the relationship between toleration and recognition, it seems apt to avoid an all-to-general dichotomy between universalism and particularism or, in other words, to reach beyond the debate between liberalism and communitarianism in political philosophy.

The paper takes as its starting point the view that the discussion on toleration and diversity in intercultural communication is one of the contexts where it seems important to get beyond the liberal/communitarian dichotomy. Some basic features of Rainer Forst's theory of toleration and Axel Honneth's theory of the struggle for recognition are presented, in order to develop a more substantial understanding of the relationship between the concepts of toleration and recognition. One lesson from Forst is that toleration is a normatively dependent concept, i.e., that it is impossible to deduce principles for toleration and its limits from a theory of toleration as such. A central lesson from Honneth is that recognition understood as a basic human need - is always conflictual and therefore dynamic.

Accordingly, a main point in the paper is that the theory of struggles for and about recognition (where struggles for designates struggles within an established order of recognition, and struggles about designates struggles that challenge established orders of recognition) may clarify what is at stake in conflicts concerning toleration and its limits. At the same time, Honneth's theory of the need for recognition seems to be a source for the kind of argumentative justifications that a just toleration are dependent on, according to Forst.

Another important point in the paper is that toleration (pace Forst) is a practice or attitude that implies taking a stance, but in a differentiated way, and that this presuppose a reflective distance towards one's own positions. To be tolerant means saying "yes" to something (the beliefs and practices that one endorses), saying "no" to something (the intolerable), but also being able to say "no, but..." to something (that which is tolerated). Intolerance means saying "no" without justifiable reasons, whereas misguided tolerance means accepting something without justifiable reasons - both attitudes may be taken to indicate that one lacks proper understanding of the reasons for holding the viewpoints that one actively endorses.

In discussing of Honneth's theory of recognition, I argue that an ability to take a stance in a differentiated way is seminal, if struggles for and about recognition are to unfold productively. In all spheres of mutual recognition (primary, secondary and tertial groups), the potential for conflicts seems to rely on an unavoidable tension between identification with the other and identification of the other as another. This is the reason why recognition - in Honneth's sense - seems to imply toleration, or at least is reliant on the same kind of self-reflective distance and ability to differentiate that is constitutive of toleration according to Forst.

Finally, I argue that the concept of "communal values" that Honneth refers to in the context of "solidarity" cannot be taken to designate a set of substantial values that are constitutive of community, but rather that important forms of recognition take place in a social space and shape cultural codes that are both the results of and the subjects of conflict. Thus while 
"culture" is conflictual and complex, "value pluralism" - including diversity of beliefs and practices - may be productive. In this context, toleration is not about avoiding or resolving conflict, but about establishing the conditions for productive conflicts, enabling an ongoing creation and reappraisal of values.

Det er korttenkt å seia at ein er for (kulturelt) mangfald så lenge det ikkje vert konfliktar av det. Den som set pris på mangfald må i det minste ta konfliktpotensialet med på kjøpet. Eller kan ein gå så langt som til å seia at ein verdset mangfald nettopp av di konfliktar kan vera verdifulle? At det ikkje dreier seg om å vera for eller mot konfliktar, men om vilkåra for at konfliktar kan utfalda seg produktivt og om kva som kan vera til hinders for dette?

Anten ein er oppteken av fårene for fragmentering, segregering og innkapsling eller om ein tenkjer at mangfald kan vera ein ressurs og opna for verdifulle individuelle og kollektive røynsler og utfaldingsmoglegheiter, er toleranse og anerkjenning nøkkelomgrep i diskusjonar om dei sosiale og politiske utfordringane ved kulturelt mangfald. Men omgrepa toleranse og anerkjenning vert ofte knytta til motsette perspektiv: Nærmar ein seg kulturelt mangfald med ei universalistisk orientering, er det ofte toleranse som vert overskrifta, medan anerkjenningsomgrepet gjerne vert brakt på bane når universalismen vert problematisert ut frå ei multikulturalistisk orientering. Dermed vert termen «toleranse» gjerne assosiert med liberale, universalistiske tilnærmingar med vekt på individ og rettar. (Jf t d McKinnon 2006) «Anerkjenning» vert på si side gjerne assosiert med kommunitaristiske tilnærmingar med vekt på fellesskap og identitet. (Jf t d Taylor $\mathrm{m}$ fl 1994)

I staden for å setja toleranse og anerkjenning opp mot kvarandre som alternative innfallsvinklar, er eg i denne artikkelen ute etter ei differensiert forståing av tilhøvet mellom toleranse og anerkjenning. Eg vil seia noko om kva toleranse og anerkjenning kan tyda og kva nytte omgrepa kan gjera i samanhenger der interkulturell kommunikasjon vert brakt på bane. Bakgrunnen er mellom anna ei oppfatning av at interkulturelle perspektiv ofte dreier seg om å overvinna ei alt for allmenn motsetning mellom universalisme og partikularisme.

Utgangspunktet hentar eg i dei teoriane om anerkjenning og toleranse som er lagt fram av høvesvis Axel Honneth og Rainer Forst. Honneth (f 1949) er professor i sosialfilosofi ved universitetet i Frankfurt am Main, medan Forst (f 1964) er professor i politisk teori same stad. Stundom vert det sagt at dei høyrer til Frankfurtskulens tredje generasjon. I alle høve er dei båe elevar av Jürgen Habermas, og tilliks med han har dei mellom anna arbeidd med à knytta den tyske tradisjonen for «kritisk teori» saman med den amerikanske pragmatismen. Ein av dei overordna problematikkane i dette er nettopp à finna koplingspunkt eller formidlingar mellom det universelle og det partikulære. På ulike, men nærskylde måtar har Honneth og Forst arbeidd med å koma vidare i høve til den diskusjonen mellom liberalisme og kommunitarisme som har dominert mykje av den politiske filosofien dei siste tretti åra (Jf Honneth 1992, særleg s 274ff og Forst 1994).

Eg vil først seia litt om kvifor nettopp diskusjonar om toleranse og mangfald syner at det er naudsynt å overvinna slike innarbeidde motstillingar. (I) Deretter vil eg presentera grunntrekk i høvesvis Forst sin teori om toleranse og Honneth sin teori om anerkjenningskamp, for slik å få eit grunnlag for å seia noko meir substansielt om tilhøvet mellom omgrepa toleranse og anerkjenning. Hjå Forst kan vi mellom anna læra noko viktig om kva implikasjonar det har at toleranse er eit «normativt avhengig omgrep», altså at ein ikkje kan utleia prinsipp for toleranse og toleransens grenser ut frà ein teori om toleranse som såvoren. Frå Honneth kan vi mellom anna henta ei forståing av det konfliktfulle ved anerkjenning som grunnleggjande menneskeleg behov. (II) Eit hovudpoeng frå mi side vil vera at teorien om anerkjenningskampen kan vera med på å klårgjera kva som kan stå på spel i konfliktar om toleranse og toleransens grenser. Samstundes er Honneth sin teori om 
«behovet for anerkjenning» ei kjelde til den slags grunngjevingar som Forst hevdar at rettferdig toleranse treng. (III) Til sist vil eg seia noko om korleis vi kan tenkja om tilhøvet mellom mangfald og fellesskap - og dermed om toleranse og solidaritet - dersom vi går ut frå at konfliktar kan vera produktive. (IV)

\section{Toleranse eller anerkjenning - eit falskt dilemma}

Det er ikkje utan grunn at toleranse og anerkjenning framstår som motsetningar - ettersom dei i utgangspunktet uttrykkjer motsette innstillingar: Ein er tolerant andsynes noko ein ikkje liker, medan anerkjenning er ei positiv haldning. Samstundes kan ein seia: «Du har meiningar eg ikkje deler, syner haldningar eg ikkje kan gå god for, gjer ting eg ikkje verdset - men eg tolererer det, ettersom du har rett til å gjera deg opp dine eigne meiningar, til å stå for haldningane dine og ta ansvar for dine eigne handlingar.» Då er toleransen uttrykk for anerkjenning. Eller også kan eg gå i rette med meiningane dine, forlanga at du endrar haldningar og sanksjonera handlingane dine - nettopp av di eg ser på deg som eit fornuftig, anstendig og ansvarleg menneske: «Eg kan ikkje tolerera dette, slikt noko lyt du halda deg for god til.» Då er kritikken uttrykk for anerkjenning. Slik kan ein sjå at det er skilnader mellom toleranse og anerkjenning, og ofte ei spenning, ettersom det ikkje er opplagt kva ein skal leggja vekt på i ulike situasjonar. Men i utgangspunktet treng det ikkje vera snakk om eit dilemma, eit anten-eller, der ein er nøydd til å gje slepp på, eller la vera å snakka om det eine når ein snakkar om hitt. Hovudpoenget i det som følgjer, er tvert om at vi kan snakka meir sakssvarande om toleranse når vi også tek omsyn til anerkjenning - og omvendt, at vi kan seia noko viktig om anerkjenning om vi òg tek omsyn til toleranse.

I diskusjonar om utfordringar - altså både problem og moglegheiter - som har å gjera med kulturelt mangfald, kan det likevel synast som ein lyt velja, eller som om ein alt har valt ein synsvinkel så snart ein tek i bruk det eine eller andre ordet. Sjølv det valet eg alt har gjort, ved å nytta uttrykket «kulturelt mangfald» heller enn «verdipluralisme» eller «forskjelligheit», kan tenkjast å setja lesaren på sporet av meir substansielle oppfatningar enn dét eg strengt teke har hatt i tankane.

Som kjent kan ein aldri seia berre éin ting, og dei nissane som til ein kvar tid er med på lasset, vil stundom undergrava føresetnadene for det ein seier. Fullt medviten om at ein knapt kan seia noko utan å ta munnen for full, vil eg hevda at spørsmålet om ein skal snakka om toleranse eller anerkjenning ikkje har så mykje med desse omgrepa å gjera, som med dét at det - i akademiske og politiske samanhengar - er ein tendens til á assosiera dei med ulike «diskursar» (språkbrukssamanhengar). Då kan det sjå ut som om det på den eine sida finst ein liberal toleransediskurs, på hi sida ein kommunitaristisk anerkjenningsdiskurs. Innafor kvar av dei er det rom for svært ulike oppfatningar av kor stort mangfald det er mogleg og ynskjeleg for eit samfunn å halda seg med, men premissane for drøftingane framstår som gjensidig utelukkande.

Dersom desse alternativa verkeleg var dei einaste vi hadde å halda oss til, var vi verkeleg ille ute, for både «toleranse» og «anerkjenning» kan inngå i talemåtar knytta til undertrykkande praksisar. Ei viktig innvending mot liberale ideologiar er påvisinga av det som vert kalla «repressiv toleranse», som når ytringsfridomen tyder at «du kan seia kva du vil, så lenge det ikkje betyr noko». Og ei viktig innvending mot kommunitaristisk ideologi, er påpeikinga av at anerkjenning av «mangfald» er ein velprøvd kolonial hersketeknikk som ikkje forsvann med avskaffinga av kolonialismen: Eit mindretal kan halda på makta ved å få fleirtalet til å identifisera seg som ei rekkje av seg imellom ulike grupper.

Det vi kan læra av dette er - for å snakka i store bokstavar - at sjølve utgangspunktet vert like feil anten vi seier at universalisme alltid er frigjerande og partikularisme alltid er 
undertrykkjande eller om vi seier det motsette. For å unngå at dikotomiseringa - som knapt er til å unngå - skal føra oss på villspor, gjeld det å kunne skjelna etter fleire dimensjonar, til dømes ved å spørja korleis omgrepa fungerer i ulike situasjonar. Då vil ein oppdaga at dei såkalla universelle prinsippa ikkje eksisterer uavhengig av at dei vert påkalte i konkrete situasjonar, medan på hi sida sjølve påpeikinga av ein partikulær identitet utgjer ein appell til noko allment. Dermed kan det vera at det er vel så relevant å spørja om kven som stiller kva for krav andsynes kven enn om terminologien dei nyttar til vanleg vert knytta til universalisme eller partikularisme.

Teoriane til Honneth og Forst er interessante av di og i den grad dei kan vera med å skjerpa sansen for kva som ligg i den daglegdagse bruken av verdiladde og omstridde omgrep. Her og no grip eg til dei for å finna leietrådar for ei gjennomtenking av tilhøvet mellom toleranse og anerkjenning. I neste omgang vil dette kasta lys over spørsmålet i tittelen min: Kva vil det seia å verdsetja mangfald? - Her gjev eg meg ut på tynnare is. Det handlar mellom anna om tilhøvet mellom toleranse og solidaritet. $\AA$ seia at ein verdset mangfald, er ikkje det same som å gjera det. Toleranse og solidaritet er sosialdemokratiske plussord, som ofte vert nemnt i same andedrag, og som i Noreg vert administrerte av Inkluderings- og mangfaldsdirektoratet. (sjå Venneslan 2007.) ${ }^{1}$ Men toleranse og solidaritet er ikkje verdiar. Som eg straks vil forklåra, er del likevel tale om verdiladde eller verdirelaterte omgrep. Dermed syner måtane vi praktiserer toleranse og solidaritet noko om korleis vi stiller oss til det vi (seier at vi) verdset.

\section{Toleranse og anerkjenning i nyare kritisk teori (Forst og Honneth)}

I dette avsnittet vil eg først gjera stutt greie for Rainer Forst sin analyse av toleranseomgrepet og den typologien han har laga: han skriv om fire ulike konsepsjonar av toleranse - i teori og praksis. Dette er henta frå boka Toleranz im Konflikt. Geschichte, Gehalt und Gegenwart eines umstrittenen Begriffs (Forst 2003). For dei som er interesserte i toleranseomgrepet, inneheld boka mykje meir lærerikt og tankevekkjande stoff, ikkje minst idéhistorisk, enn det eg dreg fram her. Deretter vil eg presentera nokre element av Axel Honneth sin teori om anerkjenning. Dette hentar eg først og fremst frå boka Kampf um Anerkennung. Zur moralischen Grammatik sozialer Konflikte (Honneth 1992). Heller ikkje her er det tale om ein gjennomgang av boka eller fullstendig utgreiing om teorien.

Toleranse er ikkje ein verdi, iallfall ikkje «i seg sjølv» og utan nærare kvalifikasjonar. Når eg seier dette, er det av di eg er samd med Forst når han karakteriserer toleranse som eit «normativt avhengig» omgrep. Det vil seia at ein ikkje kan utleia toleransens grenser og grunnlag frå ein teori om toleranse som såvore. Kva toleranse normativt sett inneberer, kjem an på kva for normer og verdiar som set grenser for kva som er akseptabelt. Toleranse er dermed eit kontekstuelt omgrep. Kva toleranse nærare bestemt tyder, og om og når det eventuelt er verdifullt å vera tolerant, er avhengig av kven som tolererer kva frå kven, når, kor og ikkje minst: Av kva grunnar. Omgrepet toleranse peikar likevel på ein problematikk som har nokså klåre konturar. Måten ein - i teori og/eller praksis - fyller ut desse konturane, gjev opphav til ulike forståingar av omgrepet - det Forst kallar «konsepsjonar» av toleranse, til skilnad frå «konseptet» toleranse.

«Konseptet» toleranse har ifølgje Forst tre grunnkomponentar: Avvising («Ablehnung»), godtaking («Akseptanz») og forkasting («Zurückweisung») (jf. Forst 2003, s 30ff). Avvisingskomponenten har å gjera med at det ein tolererer på ein eller annan måte er noko ein stiller seg negativ til, godtakinga med at ein nettopp likevel aksepterer det, medan det forkastelege er hisides grensa for det ein kan tolerera. Toleranse er dermed ikkje det same

1 Studien er ei gjennomgang av grunnlaget for «mangfaldspolitikk» som offisielt paradigme ut frå norske stortingsmeldingar og liknande offisielle dokument. 
som likesæle («indifferens»). Det handlar om å ta stilling - men om ei form for differensiert stillingstaking: Den tolerante seier 'ja' til noko og 'nei' til noko - men er også i stand til å seia 'tja' eller 'nei, men likevel...'

Det Forst kallar «toleransekonsepsjonar» dreier seg om dei praktiske og/eller teoretiske forståingane av samanhengen for og grunnane til slik differensiert normativ stillingstaking (altså høvesvis avvising, godtaking og forkasting). Desse grunnane kan, men må ikkje vera av same slag eller henga saman - og vil truleg alltid stå i eit spenningstilhøve til kvarandre. Ein utvikla toleransekonsepsjon seier dermed mykje om innhaldet i dei normene og verdiane som toleransen er avhengig av. Dessutan, og ikkje minst viktig, seier den noko om at normer og verdiar er kontekstsensitive omgrep, og om kor medviten ein er om dette.

Forst legg fram fire idealtypiske toleransekonsepsjonar: (1) «Tillatingskonsepsjonen», der ei hegemonisk gruppe toler avvikande oppfatningar og praksisar hjå eit mindretal av di og så lenge det ikkje trugar hegemoniet. (2) «Sameksistenskonsepsjonen», der grupper som ikkje er i posisjon til å dominera kvarande aksepterer føreliggjande skilnader i oppfatningar og praksisar. (3) «Respektkonsepsjonen», der toleranse vert grunngjeven i respekt for autonomien til individ og grupper. (4) «Verdsetjingskonsepsjonen», der toleranse vert grunngjeve i verdien av mangfald i oppfatningar og praksisar (Forst 2003, s 42ff). Sjølv om typologien er idéhistorisk fundert, understrekar Forst at det ikkje er tale om historiske stadium. Ulike toleransekonsepsjonar kan eksistera jamsides einannan, og sjølv om det finst overgangar mellom dei, vil han ikkje snakka om noka målretta utvikling frå den eine til den andre. Men det er verd å merka seg at dei to første er pragmatiske, medan dei to siste er knytta til prinsipielle synsmåtar.

Sjølv gjev Forst utkast til ein «kritisk teori om toleranse», som framstår som ein variant av respektkonsepsjonen ut frå ein teori om rettferd. Grunntanken er enkel: Intoleranse er å forkasta noko utan å ha gode grunnar til det. Misforstătt toleranse er à godta noko utan å ha gode grunnar til det. Båe delar kan vera symptom på at ein ikkje har klår nok forståing av kva grunnar ein har til å seia ja til sine eigne overtydingar. Gode grunnar er grunnar ein kan gjera gjensidig og likeverdig gjeldande. Om nokon tenkjer at dette minner om Kant og Habermas, så har dei skjønt kva tradisjon Forst stiller seg i.

Rettferd er i det heile det mest sentrale emnet i forfattarskapen til Rainer Forst (Forst 1994, 2007, 2011), medan anerkjenning utan tvil er gjennomgangstemaet hjå Axel Honneth. (Sjå også Hansteen 2010.) For å skjøna kvifor og korleis anerkjenning er så sentralt i tankegangen hans, er det viktig å ha klårt for seg at han går ut frå ei oppfatning av mennesket som er relasjonell og konfliktorientert. Frå Hegel - som er ein av dei mest sentrale referansane til Honneth - hentar han tanken om «krafta i det negative»: Det er erfaringa av misakting som er utgangspunktet for anerkjenningskampen. Konflikt er uunngåeleg, og kan vera produktivt. På det individuelle planet tyder dette at vi lærer oss sjølv og kvarandre betre å kjenne gjennom konfliktar, som dermed kan vera utviklande for relasjonane. På det samfunnsmessige planet er konfliktar høve til å artikulera (krav om) gjensidig forpliktande normer og verdiar. (Jf t d Honneth 2009).

Som personar - altså i dei relasjonane som gjer eit individ til eit «sjølv» - er menneskelege individ frå ei side sett unike, frå ei anna side er dei like, og frå ei tredje side er dei forskjellige. Til desse aspekta av det menneskelege, svarar det Honneth kallar tre grunnformer for anerkjenning, nemleg kjærleik, rettferd og solidaritet. Det som vert anerkjent i kjærleiken, er individet sine kroppsleg funderte behov og affektar, døme på den motsvarande forma for misakting er mishandling og valdtekt, altså krenkingar av den kroppslege integriteten. Det som vert anerkjent i rettferda, er individet som moralsk tilrekneleg person, som vert misakta dersom det vert utsett for rettstap og utelukking, som er krenkingar av den moralske integriteten. Til sist vert solidaritet forstått som «sosial 
verdsetjing», altså ei anerkjenning av individet sine (aktuelle eller potensielle) bidrag til fellesskapet; det motsette er forakt og nedvurdering, som er krenkingar av den sosiale integriteten (For eit oversyn, sjå Honneth 1992, s 211).

Dei tre grunnformene for anerkjenning - kjærleik, rettferd og solidaritet - svarer altså til tre ulike komponentar i personlegdomen, og anerkjenningskampen utspelar seg tilsvarande i tre ulike dimensjonar. I eit moderne samfunn vil desse ifølgje Honneth svara til ulike sosiale sfærar. Når Honneth skriv om kjærleik, er det dei unike relasjonane mellom unike individ etter mønster av venskap, parforhold og tilhøvet mellom foreldre og born - han har $\mathrm{i}$ tankane. Relasjonar til konkrete andre utspelar seg i primærgrupper. Rett er knytta til sfærane for moralsk og juridisk regulert samhandling, til dømes i organisasjonar og marknader, såkalla sekundærgrupper, der individa ter seg til generaliserte andre. Solidaritet har med det Honneth kallar «verdifellesskap» å gjera, som han på eine sida assosierer med arbeidet, på hi sida med demokratisk deltaking; det dreier seg i båe tilfelle om såkalla tertiærgrupper, der individa ter seg til eit abstrakt «vi» (Jf Honneth 1992, s 148 ff.) ${ }^{2}$

Når Honneth skriv om «behovet for anerkjenning», har det både ei moralpsykologisk og ei samfunnsteoretisk side: Eit minstemål av stadfesting (og vel å merka i alle dei nemnde dimensjonane) er naudsynt for at individet skal kunne utvikla adekvate relasjonar til seg sjølv og til andre. Kamp om anerkjenning er altså ikkje ein av fleire moglege relasjonar mellom individ, men forma for dei relasjonane som konstituerer menneskelege individ som personar. Dermed er det ein sterk, indre samanheng mellom sosialisering, integrasjon og sosial reproduksjon, og skal vi skjøna desse samanhengane, er det det konfliktfulle ved alle sosiale relasjonar som vert leietråden.

Eg skal ikkje her forfølgja dei vidtrekkande samfunnsteoretiske implikasjonane av dette. Som ein randmerknad vil eg likevel peika på at den dynamiske forståinga av normativitet som Honneth gjer seg til talsmann for, kan vera eit fruktbart utgangspunkt for å overvinna ei alt for abstrakt motsetning mellom partikularisme og universalisme. Kanskje vi kan gå så langt som å seia at spenninga har eit ontologisk grunnlag i menneskets sårbare kropp. Det som skil oss frå kvarandre - nettopp den kroppslege eksistensen - er samstundes det mest allmenne ved mennesket. (jf Lysaker 2013.) ${ }^{3}$

I denne samanhengen - der det handlar om tilhøvet mellom anerkjenning og toleranse gjeld det først og fremst å halda fast ved følgjande: Dersom Honneth har rett $\mathrm{i}$ at alle sosiale relasjonar har eit konfliktpotensiale, at konfliktar har i seg eit potensiale for utvikling og at dette gjer anerkjenningskamp til eit grunnleggjande omgrep for å forstå sosial, politisk og kulturell dynamikk, så vil vi stadig bli konfrontert med situasjonar som stiller krav om den forma for differensiert stillingstaking som ifølgje Forst er kjerna i omgrepet toleranse.

Dette er ikkje staden for ei allmenn utgreiing om likskap og skilnader mellom Honneth og Forst sine filosofiar. Eg vil nøya meg med eit par observasjonar, som først og fremst er interessante av di dei peikar mot problemstillingar som er interessante i seg sjølv.

Den første gjeld det historiske, der ein godt kan seia at dei omtalte bøkene av Forst og Honneth ufyller kvarandre. I alle fall vil eg meina at den idehistoriske framstillinga til Forst gjev godt grunnlag for å hevda at nettopp konfliktar om toleranse har vore viktige arenaer for produktive anerkjenningskampar. Til dømes har kampen for religionsfridom vore særs viktig for artikuleringa av sjølve idéen om allmenne menneskerettar, og historisk har dette skjedd nettopp gjennom konfliktar om ulike toleransekonsepsjonar og strid om grunnlaget

2 Tilordninga av kjærleik, rett og solidaritet til høvesvis primær-, sekundær- og tertiergrupper, er ikkje Honneth si eiga, men er etter mi meining nærliggjande og i det minste heuristisk klårgjerande.

3 Med utgangspunkt i Honneth sin anerkjenningsteori, har Odin Lysaker utvikla ei forståing av det universelle ved menneskerettane på grunnlag av menneskets sårbare kropp. 
og grensene for religiøs toleranse. Og så viser det seg - sjølvsagt - at det å anerkjenna religionsfridom som ein menneskerett ikkje fører til at slike konfliktar forsvinn.

Den andre observasjonen som eg vil framheva, er at Honneth sin teori om anerkjenningskampen etter mi oppfatning kan fungera som ein viktig leietråd for å finna ut av kva som står på spel i konfliktar om toleranse: Kva aspekt av personar sin integritet er det som er truga av dei praksisane, normene eller verdsetjingane det står strid om? Og vel å merka er dette ikkje berre av interesse for analysen av konfliktane frå tilskodarperspektivet. Dersom analysane treff, vil deltakarane kunne kjenna seg att, og artikulera krav og forventningar ved hjelp av dei. På den måten er teorien om anerkjenningskampen nettopp ei kjelde til den slags normative grunngjevingar som Forst framhevar som så viktige.

Ein kan kjempa for å bli anerkjent som på line med andre - kamp for anerkjenning innafor ein gjeldande orden - eller ein kan kjempa for endring av sjølve premissane for den gjeldande ordenen - noko vi kan kalla kamp om anerkjenning. Når det dreier seg om toleranse, vil det i det første tilfellet handla om kva eller kven som skal bli tolerert, i det andre er det sjølve grunnlaget for toleransen som står på spel. Merk: Det er ikkje berre tale om eit analytisk skilje mellom element som kan vera vanskeleg å skilje - kor skilja skal gå kan vera ein del av striden.

Slik anerkjenningskamp kan ta sikte på meir eller mindre toleranse alt etter som. Stundom ser det ut til at vi står andsynes «sirkelens kvadratur»: Den allment godtekne oppfatninga er at vi vil ha meir toleranse for mangfald og mindre toleranse for diskriminering samstundes. Konfliktar oppstår mellom anna i dei tilfella der ivaretaking av mangfald krev aktiv støtte til minoritetsgrupper, og dei ovrar seg ofte som strid om ressurstildeling: Kvifor bruka tid og pengar på å støtta samisk språk og kultur, på opplæring i nynorsk sidemål eller på morsmålsopplæring for innvandrarar? Men ein skal ikkje pirka mykje i overflata av slike stridsspørsmål før ein ser at dette like mykje handlar om sosial verdsetjing. (Jf Vangsnes 2013).

\section{Toleranse, verdsetjing og fellesskap}

Dei fleste vil ha røynsle med at primærrelasjonar kan stilla krav om differensiert normativ stillingstaking: Djupe meiningsskilnader kan setja venskap på prøve, men òg tilføra dei noko verdifullt. Familiar kan bli splitta på grunn av livssynsskilnader, eller halda saman på tross av dei. I barneoppsedinga - inkludert foreldra si sjølvoppseding - lyt ein stadig finna balansen mellom den frie utfaldinga og grensesetjinga, som båe er like naudsynte. Det er heller ikkje vanskeleg å finne døme på at omgrepet toleranse kjem på banen når slike ting vert drøfta. Truleg vil ein òg kunne finne kvardagslege døme på alle dei fire idealtypiske toleransekonsepsjonane Forst gjer rekning med. Samstundes ligg det i saka sjølv - det er tale om unike relasjonar mellom unike individ - at det vil vera grenser for kor prinsipielle synsmåtar som kan gjera seg gjeldande. Som ein konsekvens av dette, tilskriv ikkje Honneth kjærleiken det same «utviklingspotensialet» som dei andre anerkjenningsformene har ved seg: Kamp om anerkjenning i den moralske og rettslege dimensjonen, mogleggjer univeralisering og materialisering av rettar, medan anerkjenningskampen i den sosiale og politiske dimensjonen mogleggjer individualisering og egalisering, meiner han. Med andre ord: Vi kan ikkje venta at kjærleiken vert utgangspunkt for artikulering av allment forpliktande normer og verdiar.

Eg trur likevel at dei fenomena eg nyss nemnde som døme på korleis toleranseproblematikken dukkar opp i primærrelasjonane kan setja oss på sporet av noko som gjeld for alle anerkjenningsdimensjonane. Det kjærleiken har med anerkjenningskamp å gjera, er ei uunngåeleg spenning mellom å identifisera seg med den andre og å stadfesta den andre som ein annan. Båe delar er naudsynte moment i stadfestinga av kroppsleg funderte behov 
og affektar. Sjølv vil eg meina - og eg trur det er i tråd med Honneth si oppfatning - at noko tilsvarande gjeld $\mathrm{i}$ alle dei tre anerkjenningsdimensjonane: Ein lyt vera i stand til a identifisera seg med andre samstundes som ein ser den andre som ein annan.

Tanken om anerkjenning som grunnlag for adekvate sjølvrelasjonar kan seia noko om vilkåra for utvikling av toleranse som personleg haldning eller «dygd», som ifølgje Forst føreset ei særskilt form for autonomi. (Forst 2003, s 656 og ff.) - Dette er viktig både for kvardagsetikken (familie, nabolag, arbeidsplassar og organisasjonar) og for profesjonsetikken. Profesjonsutøvaren formidlar verdiar og forvaltar normer i møte med individ, og lyt vera i stand til å anerkjenna desse individa i alle dei tre nemnde dimensjonane; ivareta integriteten deira - gjennom å vera venleg, rettferdig og verdsetjande i møtet med dei. Noko som føreset profesjonell og personleg integritet hjå profesjonsutøvaren sjølv. Dersom den andre er svært eller påfallande annleis enn ein sjølv, krev dette nettopp toleranse $\mathrm{i}$ tydinga evne til differensiert stillingstaking, som på si side føreset at ein har ein refleksiv avstand til sine eigne praksisar, overtydingar og verdiorienteringar. Personleg integritet forstått som sjølvtillit, sjølvrespekt og sjølvkjensle - er eit vilkår for dette, og vert nettopp utvikla i møtet med andre. Og vel å merka særleg gjennom møte med andre som er annleis enn meg sjølv - noko som vil vera ein grunn til å verdsetja mangfald...

Oppsummerande kan vi seia at eitt av møtepunkta mellom omgrepa toleranse og anerkjenning - iallfall ut frå Forst og Honneth sine teoriar - er kor avgjerande evna og viljen til differensiert stillingstaking er for at konfliktar skal kunne utfalda seg produktivt. Det siste spørsmålet eg då vil reisa - utan å kunne gjera meir enn å peika på moglege retningar for vidare drøfting - er kva konsekvensar dette kan ha for tenkinga om fellesskap. Hjå Honneth, som er den av dei som har skrive mest om dette, er nøkkelomgrepet «solidaritet». Dei abstrakte fellesskapa på tertiærgruppenivå vert haldne saman i kraft av den forma for gjensidig anerkjenning som ovrar seg konkret som sosial verdsetjing av den einskilde sine bidrag til det felles beste. Difor skriv Honneth òg om «verdifellesskap». På ein måte er dette logisk nok, for gjensidig verdsetjing føreset vel at vi i det minste har nokre verdiar sams.

Slik Honneth nyttar omgrepet handlar solidaritet om anerkjenning av skilnader. I utgangspunktet dreier det seg ikkje om det vi vanlegvis tenkjer på som kulturelle skilnader, men om «evner og eigenskapar» som gjer at individa på kvar sine vis bidreg til fellesskapen. Dei paradigmatiske døma på anerkjenningskamp i denne samanhengen vil vera arbeidarrørsla sin kamp for faglege rettar og kvinnerørsla sin kamp for likestilling. Forståinga av desse sosiale rørslene vert ifølgje Honneth forkorta dersom vi trur det berre handlar om fordelingsrettferd og juridiske rettar: Både kva ein har i lønningsposen og kva rettskrav ein kan gjera gjeldande er også uttrykk for sosial verdsetjing. Og ikkje minst har både arbeidar- og kvinnerørsla historisk sett utfordra rådande verdiorienteringar, slik at vi ikkje berre har hatt med kamp for anerkjenning, men òg med kamp om anerkjenning à gjera. Dermed burde det vera klårt at omgrepet «verdifellesskap» ikkje står for eit sett av substansielle verdiar som er konstituerande for fellesskapen, men heller om at viktige former for anerkjenning finn stad i eit sosialt rom og avleirar seg i kulturelle kodar. Desse er både resultat av og emne for anerkjenningskamp.

Slik sett er «kultur» alltid både konfliktfull og samansett. Harmoniserande førestillingar er nesten alltid uttrykk for ei eller anna form for hegemoni. Det kan endåtil gjelda om ein dyrkar «mangfald» på ein ureflektert måte. Det viktigaste er ikkje den offisielle vedkjenninga til visse verdiar, men dei røynlege praksisane: Feiring av folkloristisk mangfald kan ikkje kompensera for diskriminering på arbeids- og bustadmarknaden.

I ein artikkel om Dewey si oppfatning av demokrati, skriv Honneth beint ut at «verdipluralisme» er ikkje berre uunngåeleg dersom vi verdset autonomi, men noko som er produktivt dersom vi forstår demokrati som «refleksivt samarbeid». Når Honneth òg skriv 
om «posttradisjonelle fellesskap», trur eg han er på sporet av ei slik oppfatning av «verdifellesskap». (Jf Honneth 2000.) Eg tenkjer slik: Hisides alternativa «mangfald» som substansiell «verdi» og «verdimangfald» som «pluralismens faktum», treng vi ei verdsetjing av mangfald som vilkår for skaping og omvurdering av verdiar: Rett forstått handlar toleranse korkje om å unngå eller à bilegge konfliktar, men om å etablera vilkår for at konfliktar kan utfalda seg produktivt. 


\section{Referanser}

Forst, R.. (1994). Kontexte der Gerechtigkeit - Politische Philosophie jenseits von Liberalismus und Kommunitarismus. Frankfurt/Main: Suhrkamp.

Forst, R. (2003). Toleranz im Konflikt - Geschichte, Gehalt und Gegenwart eines umstrittenen Begriffs. Frankfurt/Main: Suhrkamp.

Forst, R. (2007). Das Recht auf Rechtfertigung - Elemente einer konstruktivistischen Theorie der Gerechtigkeit. Frankfurt/Main: Suhrkamp.

Forst, R. (2011). Kritik der Rechtfertigungsverhältnisse - Perspektiven einer kritischen Theorie der Politik. Berlin: Suhrkamp.

Hansteen, H.M. (2010). Axel Honneth - anerkjenningskamp og demokrati. I: J. Pedersen, (red.) Moderne politisk teori. Oslo: Pax.

Honneth, A. (1988). Kritik der Macht - Reflexionsstufen einer kritischen Gesellschaftstheorie. Frankfurt/Main: Suhrkamp.

Honneth, A. (1992). Kampf um Anerkennung - Zur moralischen Grammatik sozialer Konflikte. Frankfurt/Main: Suhrkamp.

Honneth, A. 2000: Das Andere der Gerechtigkeit. Aufätze zur praktischen Philosophie. Frankfurt/Main: Suhrkamp.

Honneth, A. 2009: Mellom Aristoteles og Kant. Skisse til anerkjennelsens moral. [overs. M.E. Selvik]. I: Agora nr 4, 2009 s 159-176.

Lysaker, O. (2013). Menneskeverdets politikk - Anerkjennelse av kroppslig krenkbarhet. Oslo: Abstrakt forlag.

McKinnon, C. (2006). Toleration: A Critical Introduction. London/New York: Routledge.

Taylor, C. $\mathrm{m}$ fl (1994). Multiculturalism. Examining the Politics of Recognition. Princeton, N.J.: Princeton University Press.

Vangsnes, Ø. A. (2013). Språkleg toleranse i Noreg - Norge, for faen. Oslo: Samlaget. Venneslan, K. (2007). Det nye Norge. Om integrerings- og mangfoldspolitikk. Bergen:

Gruppe for sosialfilosofi og politisk teori [Skriftserie, 2007/4].

NB: Dei nemnde bøkene av Honneth og Forst er omsette til engelsk, Forst 2007 også til svensk, Honneth 1994 også til norsk. Agora nr 4, 2009, er eit temanummer med artiklar om og av Axel Honneth på norsk. 